
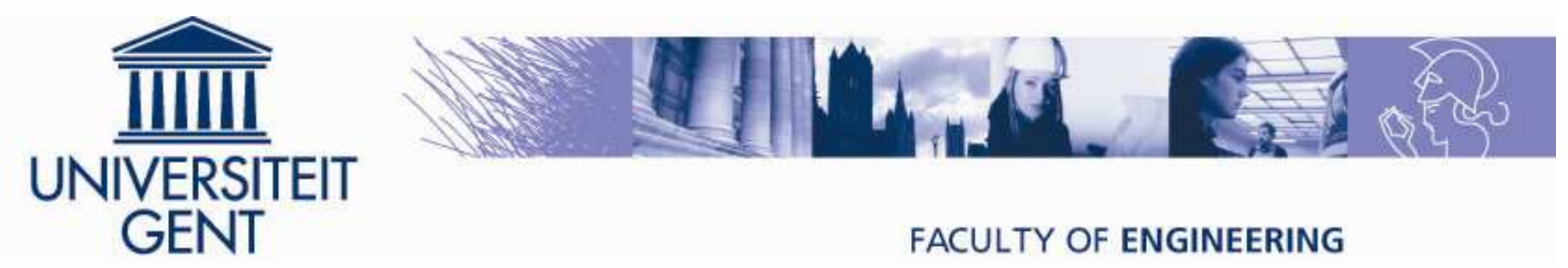

\title{
Experimental investigation of a Rotating Fluidized Bed in a Static Geometry
}

\author{
$2^{\text {nd }}$ European Process Intensification Conference \\ 14-17 June 2009 \\ Venice, Italy
}

\begin{abstract}
Rahul P. Ekatpure, Geraldine J. Heynderickx, Axel de Broqueville and Guy B. Marin
\end{abstract}

Laboratory for Chemical Technology 
- Introduction

- Concept of Rotating Fluidized Bed in a Static Geometry (RFB-SG)

- Experimental set-up and its operation

- Results and discussion

- Overall pressure drop

- Maximum solid particles capacity

- Solid particles velocity

- Void fraction

- Conclusions 


\section{Introduction}

Gravitational fluidized bed reactors

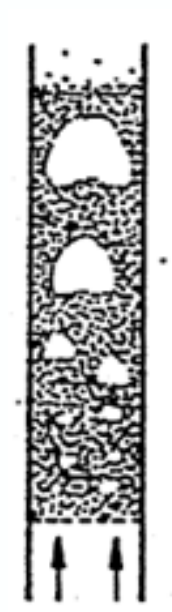

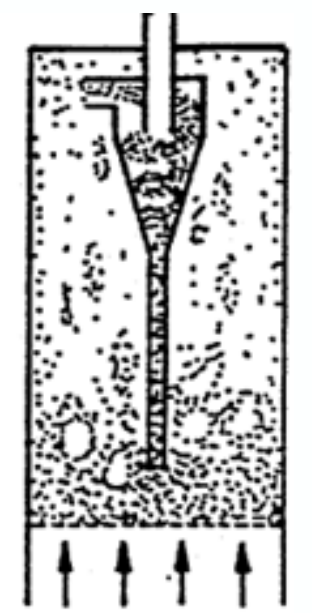

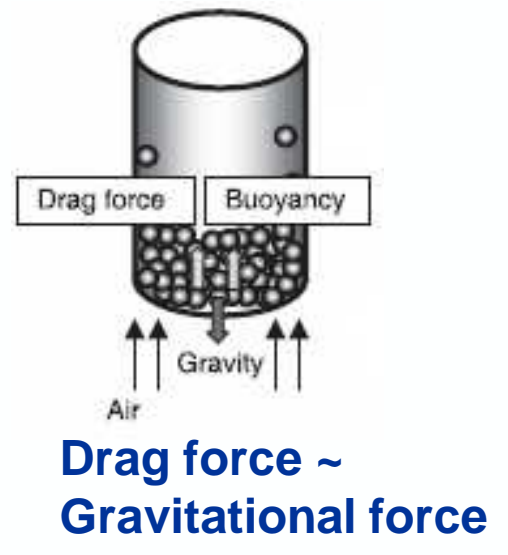

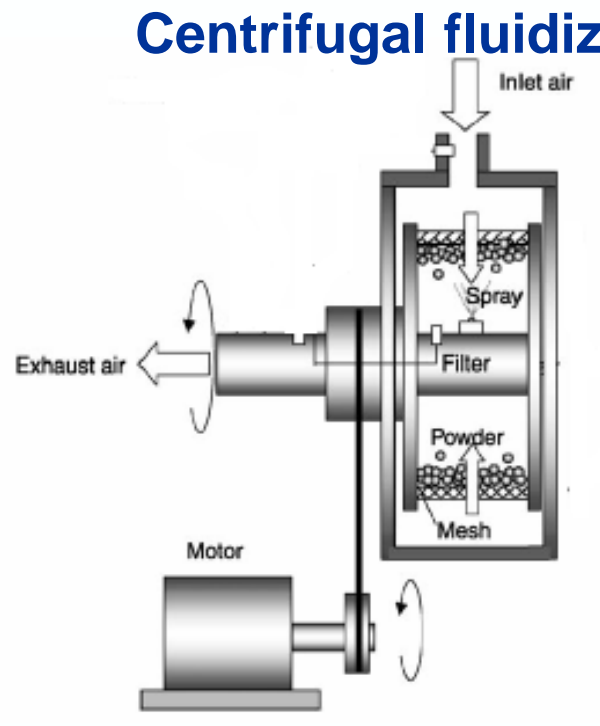

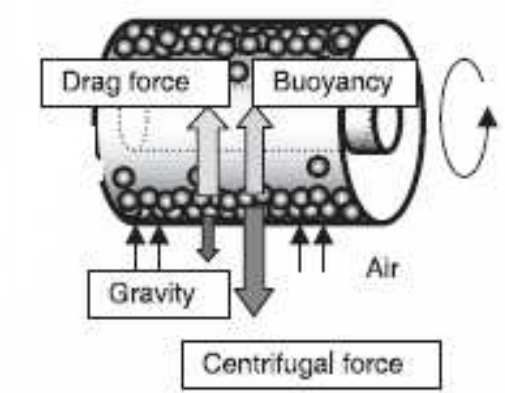

Drag force

Centrifugal force

Advantages of centrifugal fluidization in gas-solid operations

- Higher slip velocity, therefore, high heat and mass transfer at the particle scale

- Uniform temperature distribution at the reactor scale

- Ability to work at high feed flow rates

\section{General applications of centrifugal reactors}

- For short gas-solid contact time operations

- Drying, polymerization, fluidization of nano-particles, agglomeration, gas-solid separation, dust emission control 


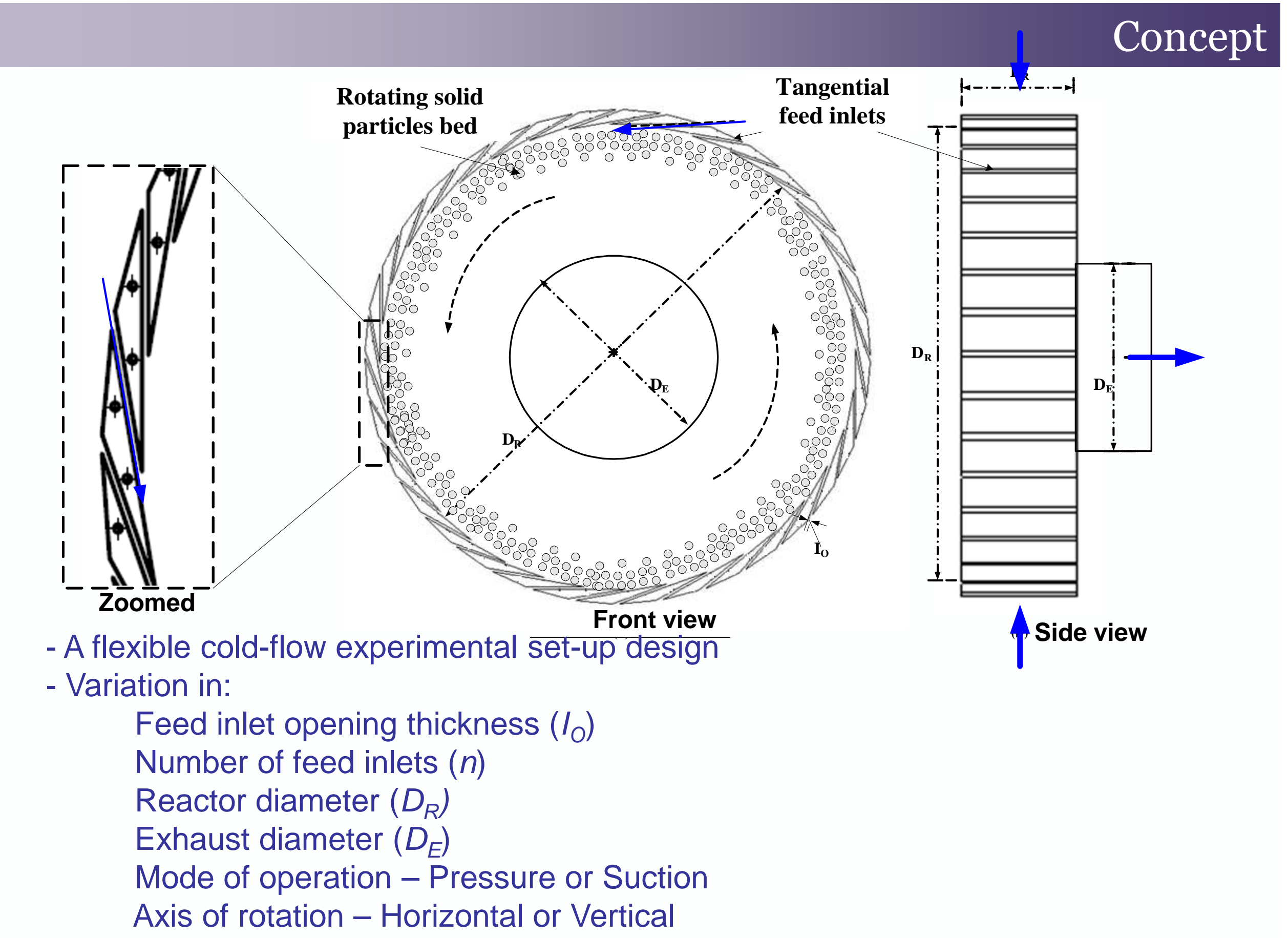


Concept

- Variation in:

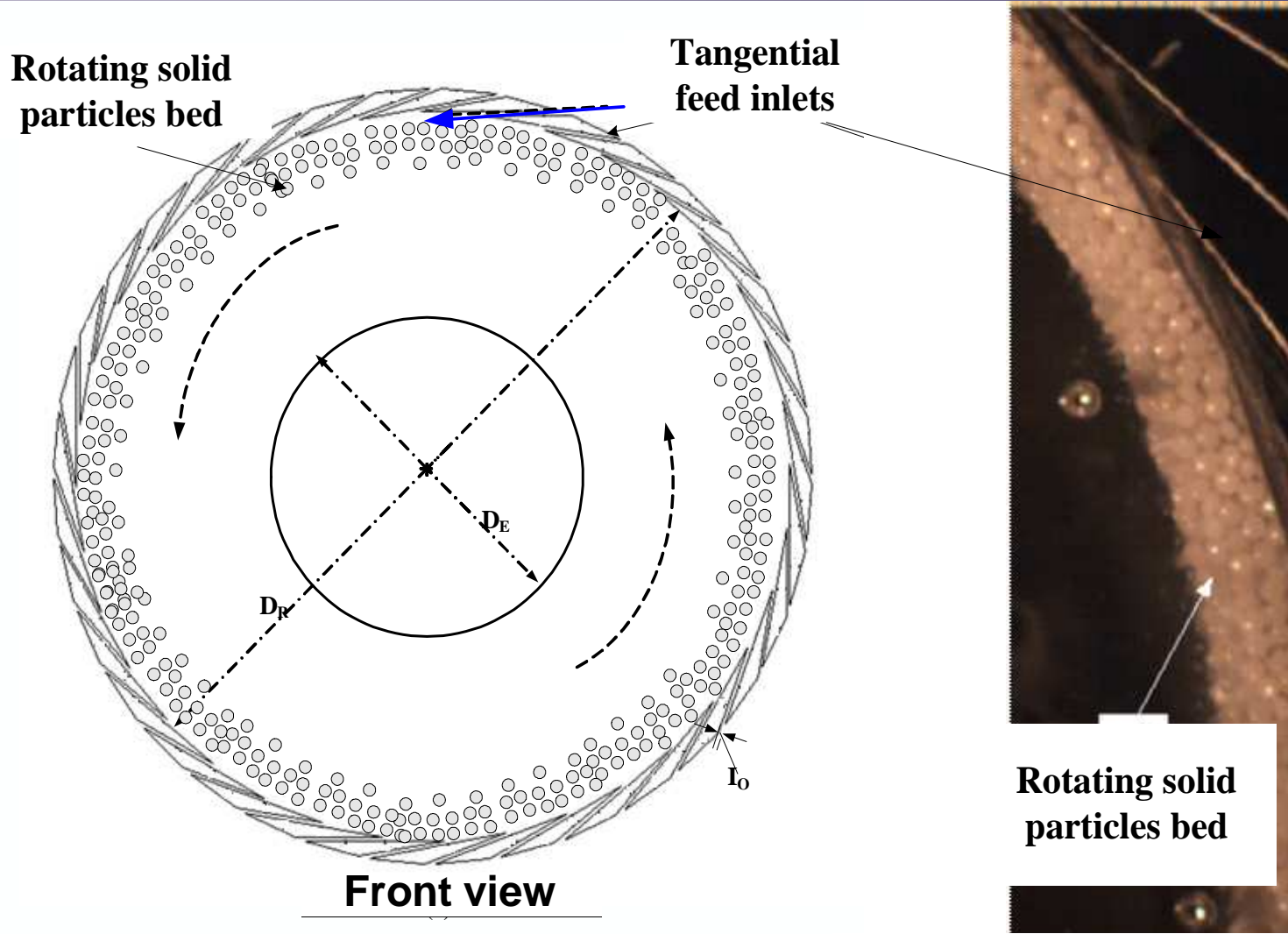

Gas flow rate Solids feed rate

Snapshot of stable rotating bed

Solids content

Solid particles size

Solid particles density

- Goal is to obtain a stable axisymmetric rotating bed of solid particles 


\section{Experimental set-up}

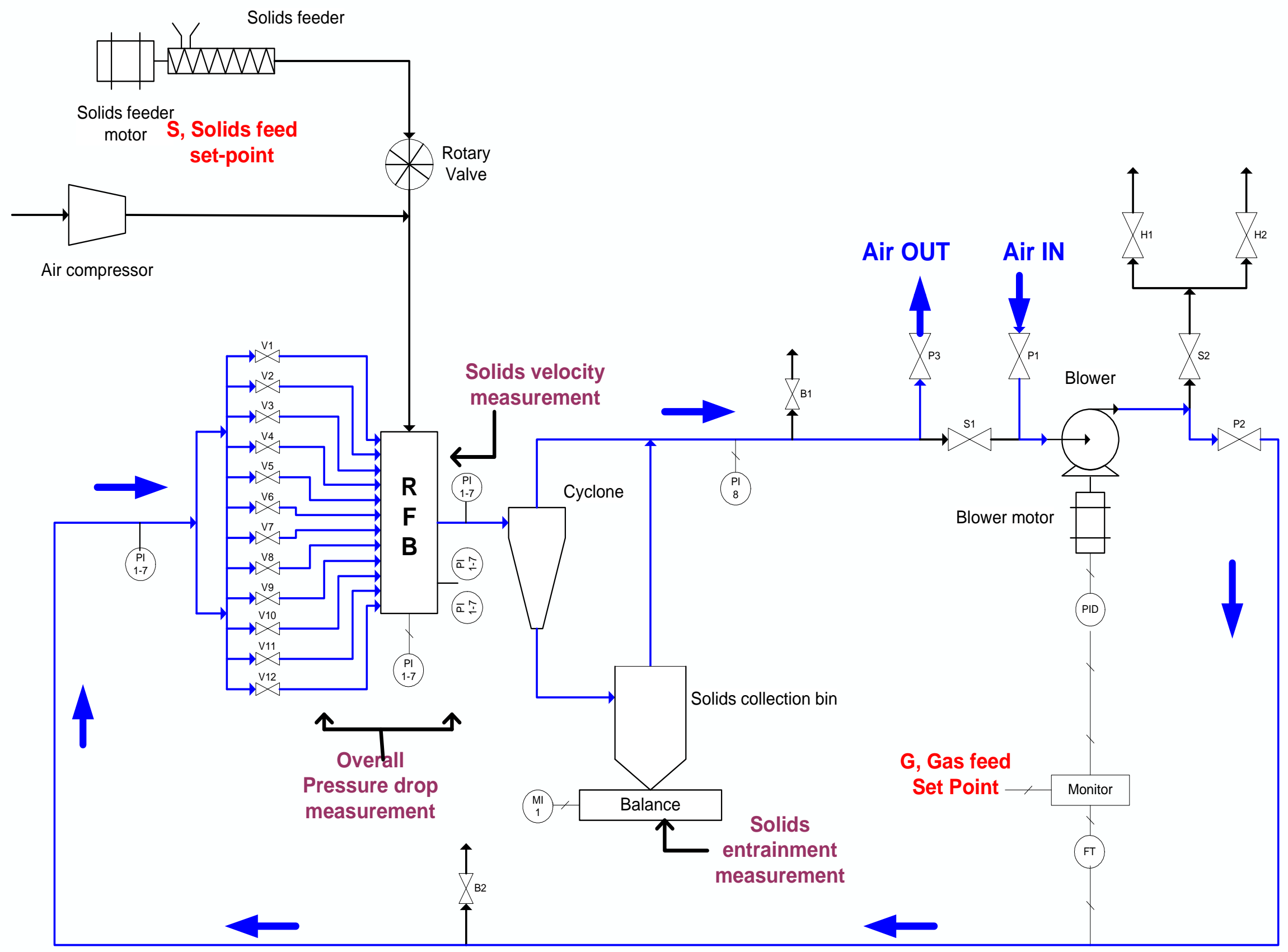




\section{Typical operation \& conditions}

\begin{tabular}{|c|c|}
\hline $\begin{array}{c}\text { Independent } \\
\text { geometrical variables }\end{array}$ & Value \\
\hline Reactor diameter & $0.54 \mathrm{~m}$ \\
\hline $\begin{array}{c}\text { Feed inlet opening } \\
\text { thickness }\end{array}$ & $0.002 \mathrm{~m}$ \\
\hline Number of inlets & $36(-)$ \\
\hline Mode of operation & Pressure \\
\hline Axis of rotation & Horizontal \\
\hline
\end{tabular}

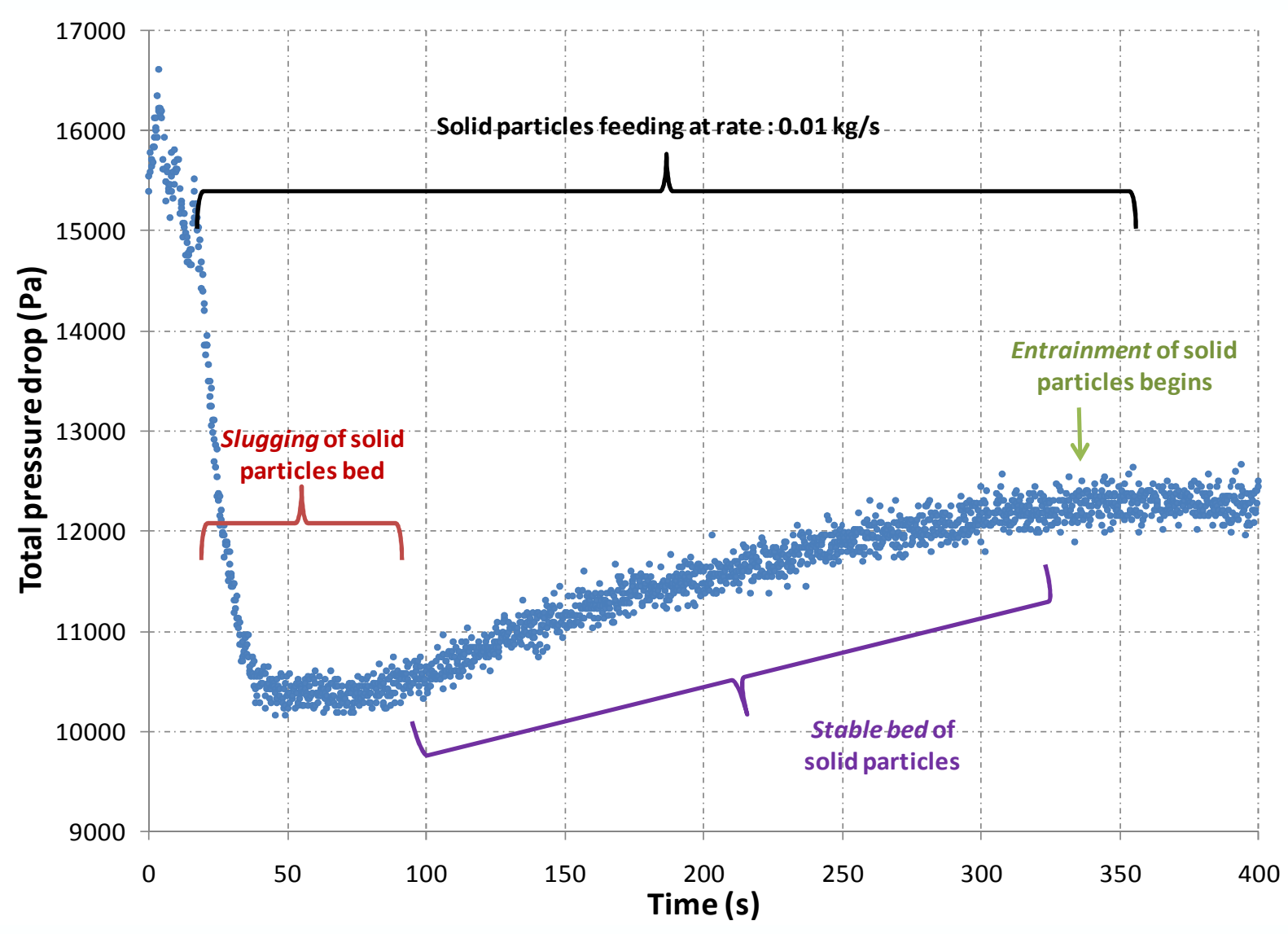

\begin{tabular}{|c|c|}
\hline $\begin{array}{c}\text { Independent } \\
\text { operating variables }\end{array}$ & Range \\
\hline Air flow rate & $0.4 \mathrm{~kg} / \mathrm{s}$ to $1.2 \mathrm{~kg} / \mathrm{s}$ \\
\hline Solid particles size & $0.9 \mathrm{~mm}$ to $3 \mathrm{~mm}$ \\
\hline Solid particles density & $950 \mathrm{~kg} / \mathrm{m}^{3}$ \\
\hline Solids content & $0.5 \mathrm{~kg}$ to $6 \mathrm{~kg}$ \\
\hline
\end{tabular}

\begin{tabular}{|c|c|}
\hline Dependent variables & Measurement technique \\
\hline Pressure drop & $\begin{array}{c}\text { Pressure probe and } \\
\text { sensors }\end{array}$ \\
\hline Solid content & Real time weighing balance \\
\hline Solid particles bed height & High speed camera \\
\hline Solid particle velocity & High speed camera \\
\hline
\end{tabular}




\section{Outline}

- Introduction

- Concept of Rotating Fluidized Bed in a Static Geometry (RFB-SG)

- Experimental set-up and its operation

- Results and discussion

- Overall pressure drop

- Maximum solid particles capacity

- Solid particles velocity

- Void fraction

- Conclusions 


\section{Total pressure drop behavior}

- Contributions in the total pressure drop

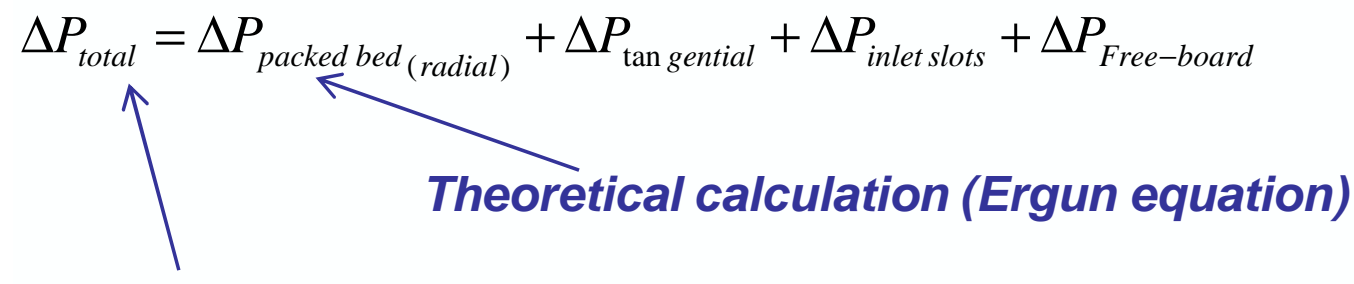

\section{Experimentally measured}

\section{Notations:}

- Ergun equation for packed bed pressure drop (Radial pressure drop)

$$
\Delta P_{\text {packed bed }}=\phi_{1} U_{0} r_{0} \ln \left(\frac{r_{0}}{r_{i}}\right)+\phi_{2} U_{0}^{2} r_{0}^{2}\left(\frac{1}{r_{i}}-\frac{1}{r_{0}}\right)
$$

where,

$$
\begin{aligned}
& \phi_{1}=\frac{1650(1-\varepsilon) \mu}{d_{p}^{2}}, \quad \phi_{2}=\frac{24.5(1-\varepsilon) \rho_{g}}{d_{p}}, \\
& U_{0}=\frac{G}{\pi D_{R} L_{R}}
\end{aligned}
$$

\begin{tabular}{ll}
\hline$d_{p}$ & Mean particle diameter $(\mathrm{m})$ \\
$D_{R}$ & Diameter of the reactor $(\mathrm{m})$ \\
$L_{R}$ & Axial length of the reactor $(\mathrm{m})$ \\
$G$ & Volumetric gas flow rate $\left(\mathrm{m}^{3} / \mathrm{s}\right)$ \\
$r_{0}$ & Outer radius of packed bed $(\mathrm{m})$ \\
$r_{i}$ & Inner radius of packed bed $(\mathrm{m})$ \\
$U_{0}$ & Superficial gas velocity $(\mathrm{m} / \mathrm{s})$ \\
$\Delta P$ & Pressure drop $(\mathrm{Pa})$ \\
\hline \hline$\varepsilon$ & Void fraction $(-)$ \\
$\rho_{g}$ & Density of gas $\left(\mathrm{kg} / \mathrm{m}^{3}\right)$ \\
$\mu$ & Gas viscosity $(\mathrm{kg} / \mathrm{ms})$ \\
\hline
\end{tabular}




\section{Overall pressure drop behavior}

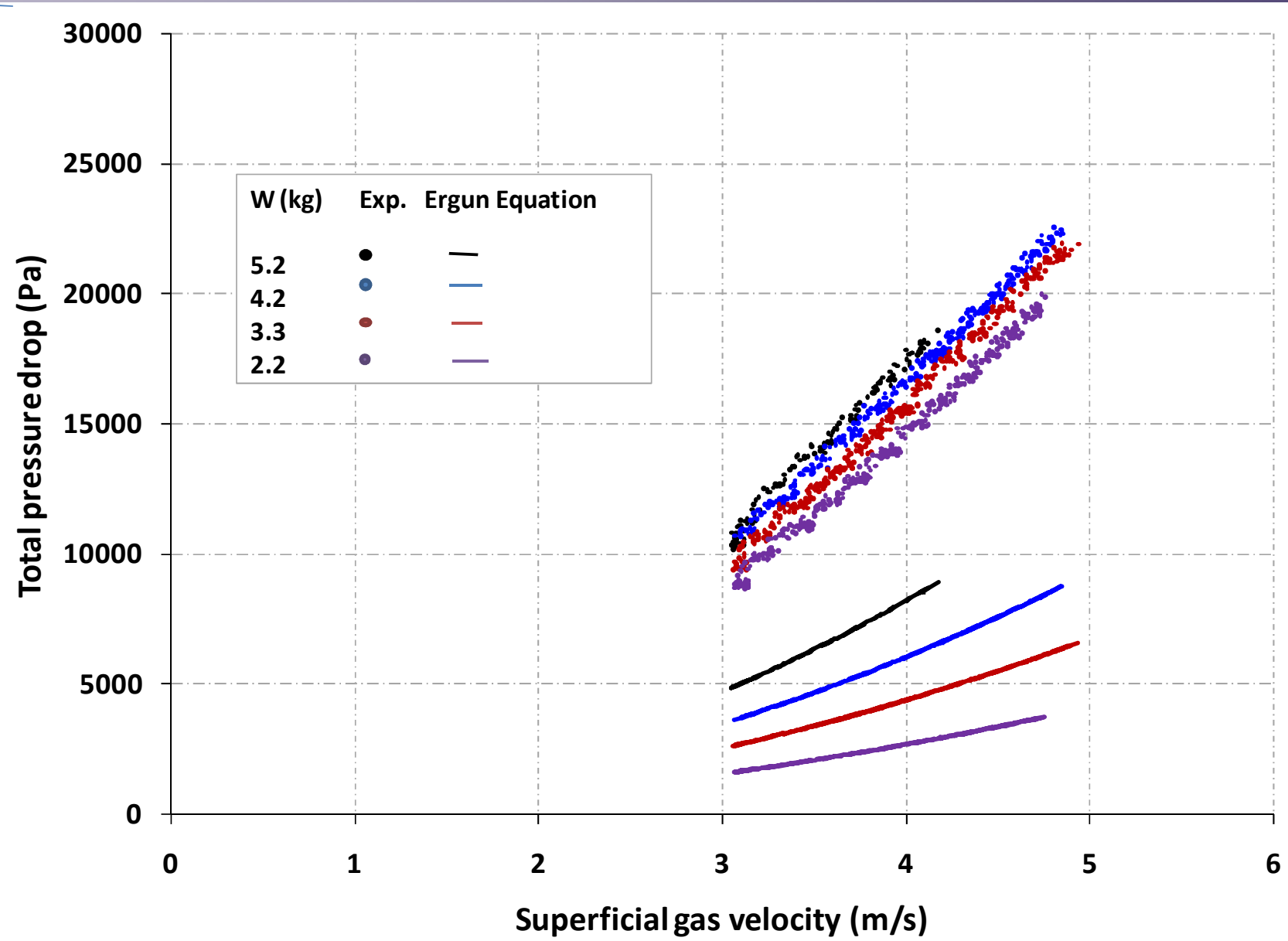

Total pressure drop v/s superficial gas velocity at various solids content for solid particles with size : $3 \mathrm{~mm}$

- Pressure drop behavior is the signature of the flow in the reactor

- As the solids content increases, overall bed height increases, leading to an increased pressure drop 


\section{Overall pressure drop behavior}

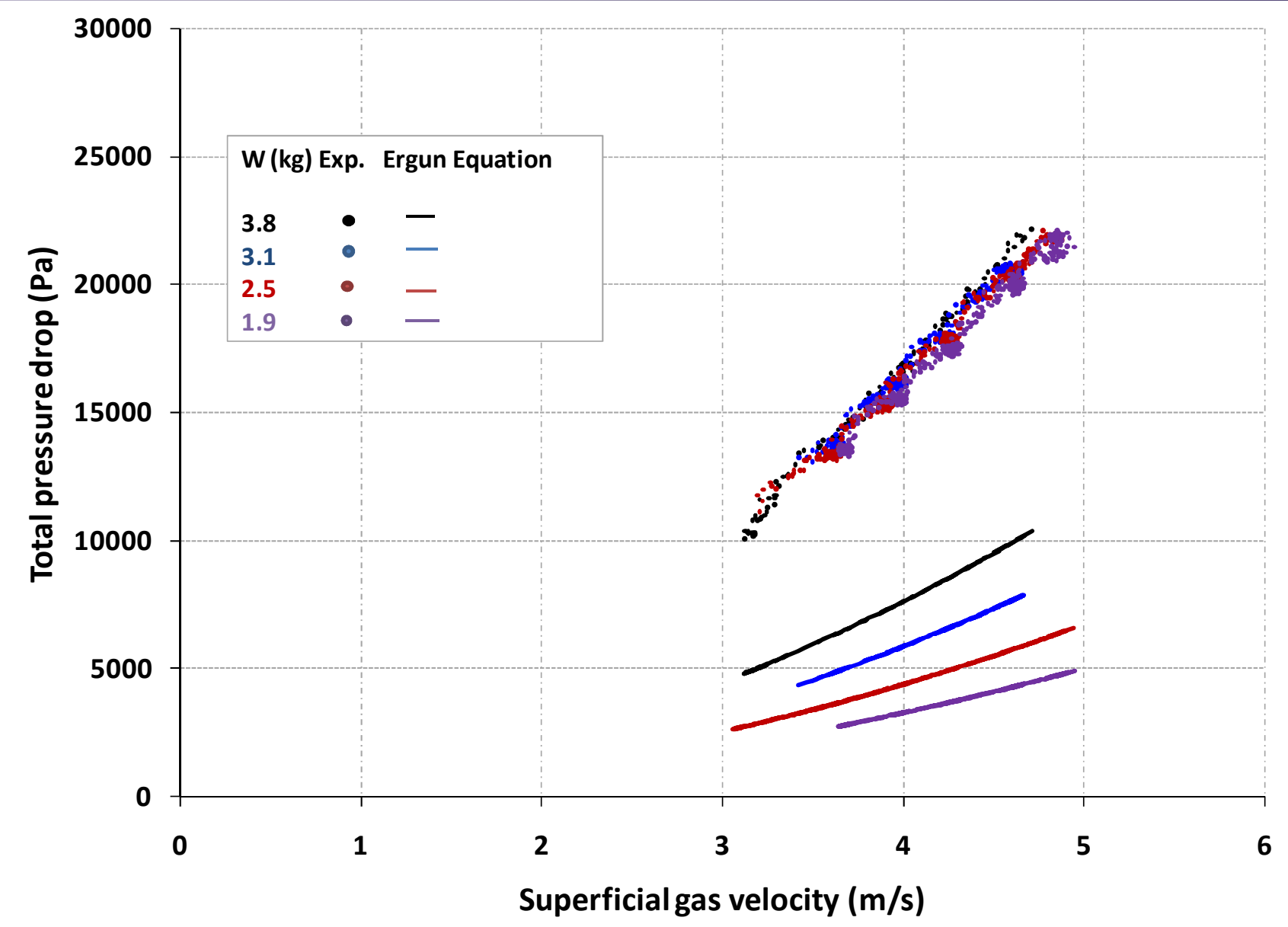

Total pressure drop v/s superficial gas velocity at various solids content for solid particles with size : $1.6 \mathrm{~mm}$

- Similar behavior of pressure increase observed for different particle size 


\section{Overall pressure drop behavior}

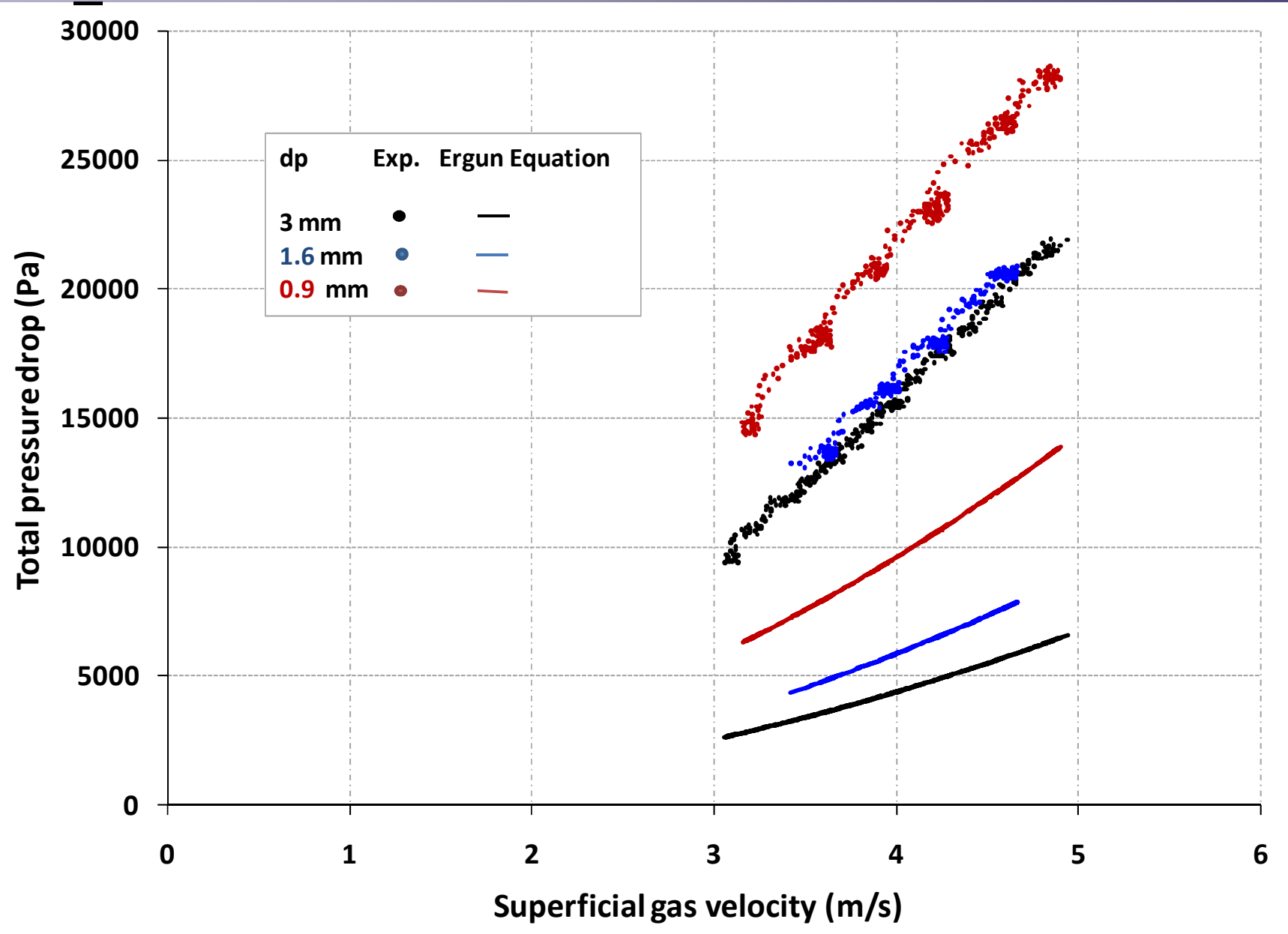

Total pressure drop v/s superficial gas velocity at various solid particles size, and constant solids content of $3 \mathrm{~kg}$

- Decrease is solid particle size, increases the specific surface area, this is leads to increase in radial drag forces, resulting into to higher pressure drop across the solid particles bed 


\section{Maximum solids content in the reactor}

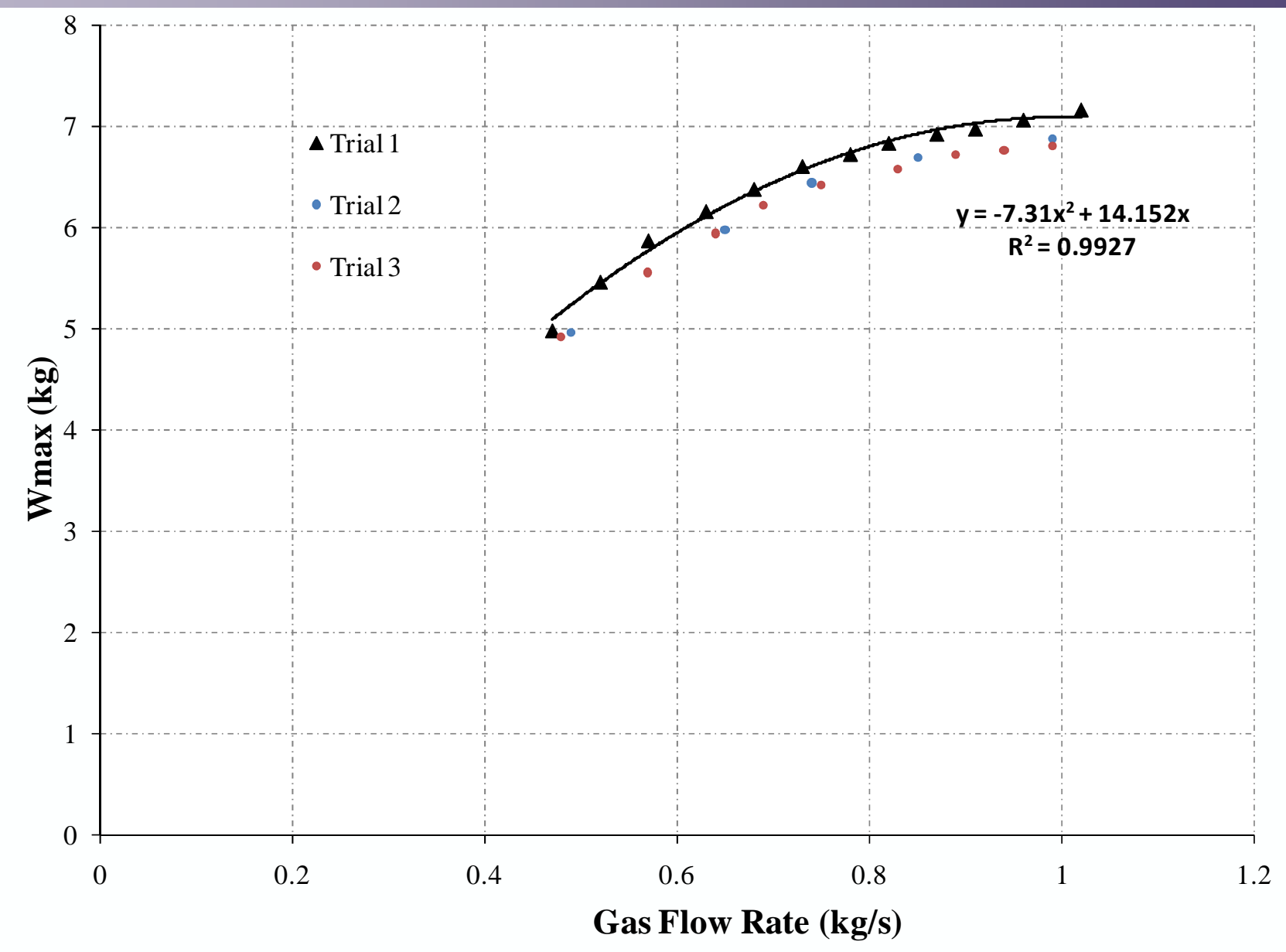

- Maximum solids content gives an idea about average solids residence time (for drying operations), and space velocity (WHSV)

- Increasing gas flow rate increases the maximum solids capacity of the reactor

- This is one of the distinct feature of RFB-SG compared to gravitational fluidized bed reactors 


\section{Maximum solids content in the reactor}

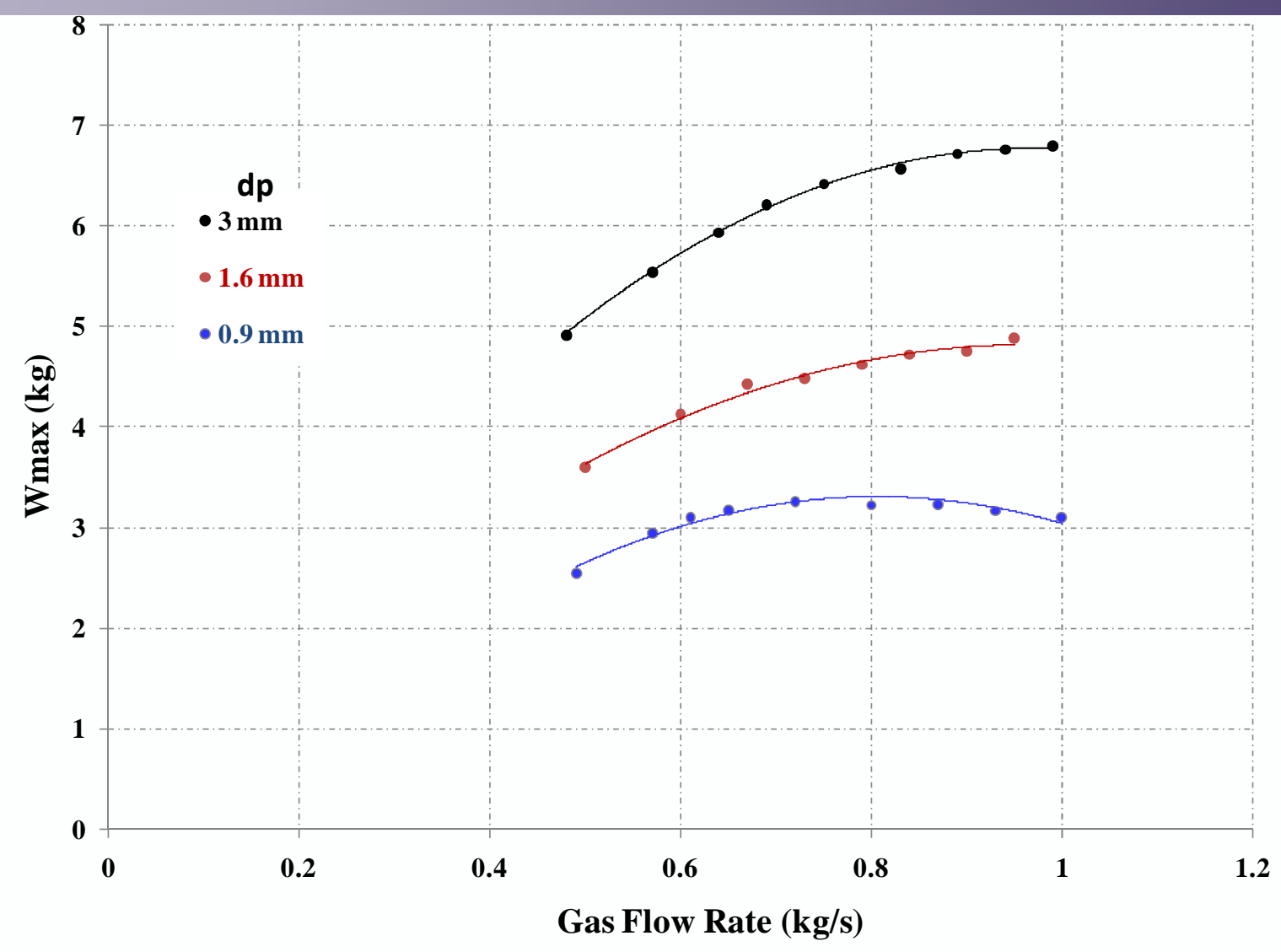

- At maximum solids content, centrifugal force is balanced by the gravity, resulting into entrainment of solid particles from the topmost position of the reactor exhaust

- Increasing gas flow rate, increases the centrifugal force, leading to increase in solids capacity until equilibrium with gravity is reached

- At lower particle size ( $0.9 \mathrm{~mm})$, radial drag force is dominant, resulting into early entrainment of solids from lateral positions of the reactor 


\section{Solid particles velocity measurement}

- Solids particle tracking by means of high-speed camera

- Measurement of solids velocity at several independent variables

- Image capturing at 3000 to 30000 frames per second

- Tracked particles further processed in $x-y$ coordinate domain (only 2D measurements)
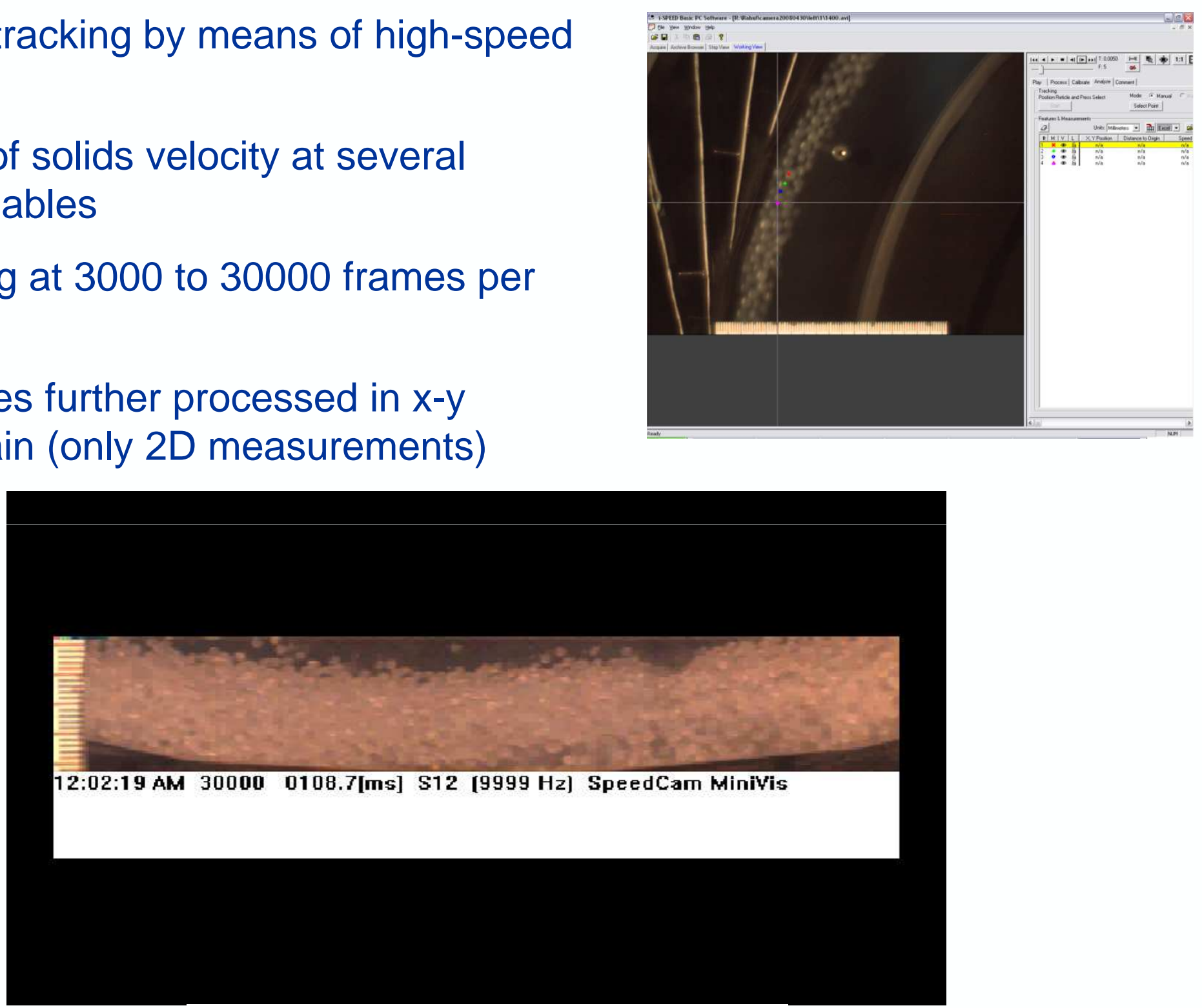

Solid particles flow captured by high-speed camera 


\section{Solid particles velocity}

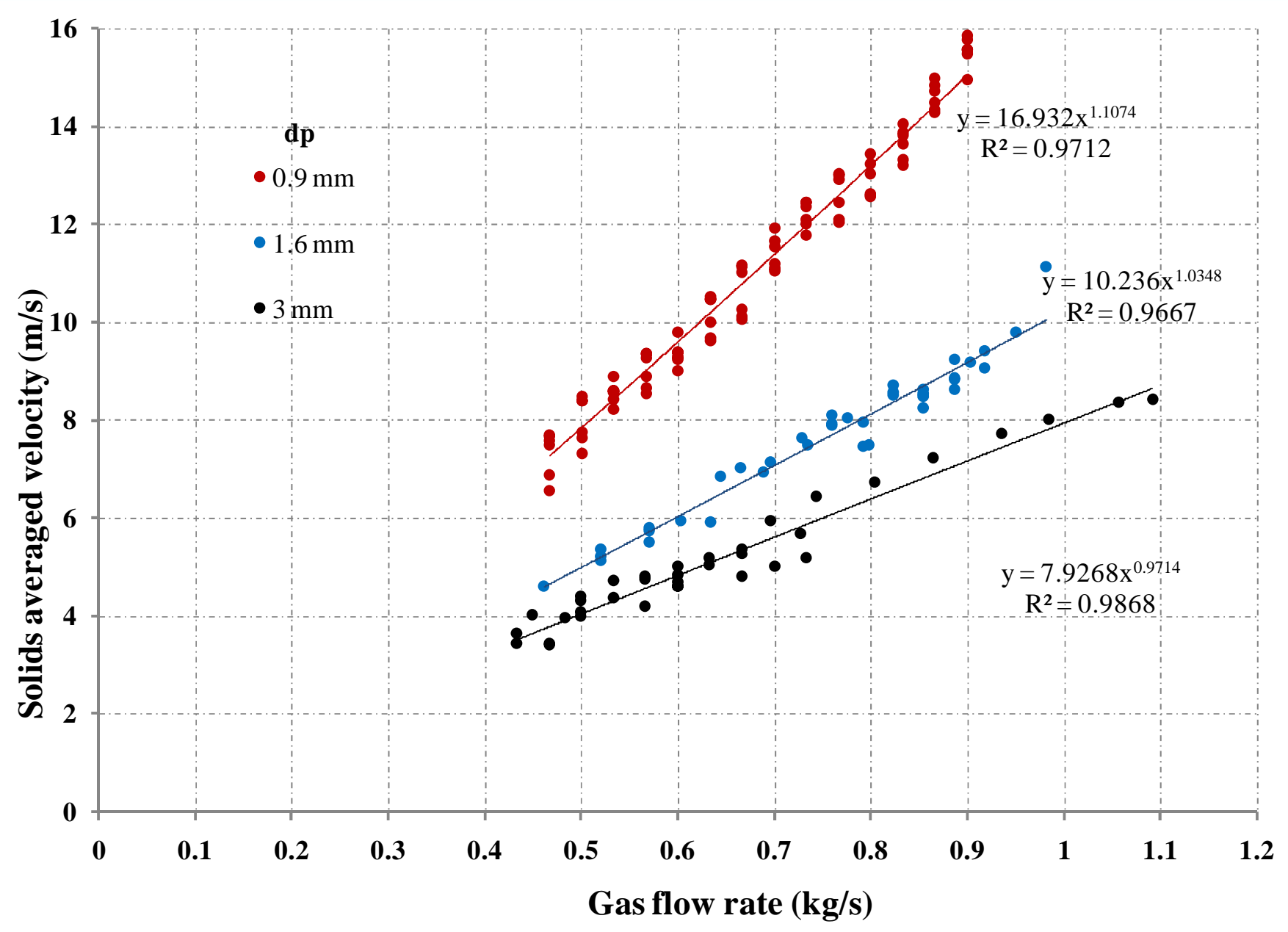

- Decrease in particle size, results into increase in the solid particles velocity

- Increase in radial drag due to decrease in particle size is compensated by higher centrifugal force, and hence higher solid particles velocity 


\section{Void fraction}

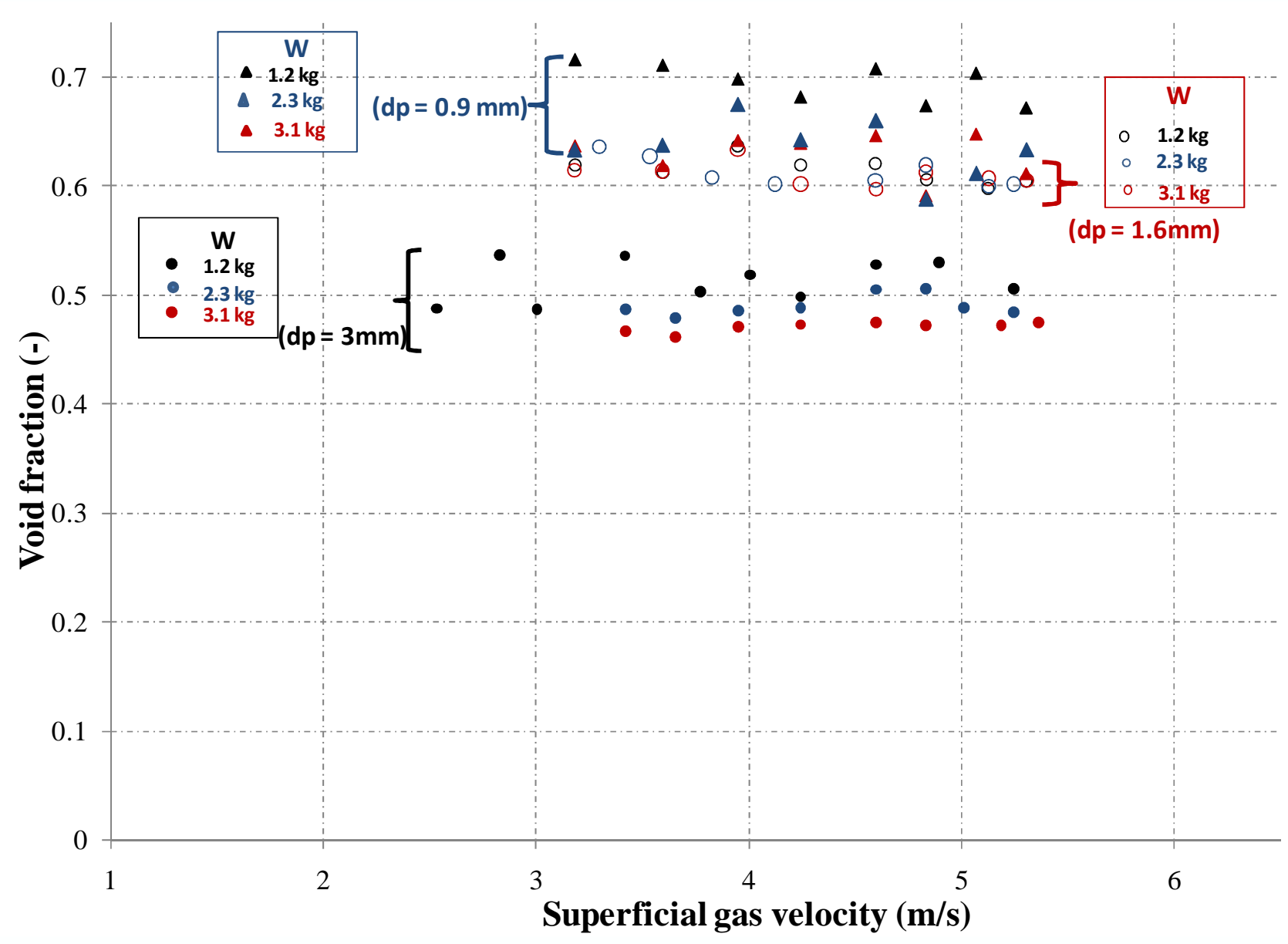

- Under investigated operating range, negligible change in void fraction is observed with varying gas flow rate

- This may be due to the constant ratio of centrifugal force to radial drag force, at given radial position, with varying gas flow rate 


\section{Conclusions}

- A flexible experimental set-up was designed and built for the experimental investigation of the RFB-SG at wide range of operating conditions

- A stable solid particles bed was achieved under investigated operating range

- For given solid particles, total pressure drop increases with increasing solids content

- For given solids content, total pressure drop increases with decreasing particle $\underline{\text { size }}$

- Maximum solids capacity increases with increasing gas flow rate for given solid particles

- Solids velocity shows linear dependence on gas flow rate

- Solids volume fraction remains almost constant for given solids content, with varying gas flow rate 